\title{
LENDO PELO OLHO MÁGICO
}

READING THROUGH THE MAGICAL EYE

\author{
Maria Cecília MOLLICA \\ Universidade Federal do Rio de Janeiro \\ ceciliamollica@terra.com.br \\ Andreia Cardozo QUADRIO \\ Universidade Federal do Rio de Janeiro \\ andreiaquadrio@gmail.com \\ Hadinei Ribeiro BATISTA \\ Universidade Federal do Rio de Janeiro \\ hadinei@gmail.com \\ Mariangela MAIA \\ Universidade Federal do Rio de Janeiro \\ mariangela.saude@gmail.com \\ Marisa LEAL \\ Universidade Federal do Rio de Janeiro \\ marisabbleal@gmail.com
}

Resumo: O presente artigo traz reflexões no âmbito do letramento escolar e social na era da cibercultura. Composto de várias seções, as discussões perpassam o impacto das tecnologias digitais na formação do sujeito leitor, na complexidade e amplitude dos níveis de letramento, bem como provoca reflexões quanto à veracidade das múltiplas vozes que discursam na internet e nas redes sociais. De forma mais estreita com o trabalho escolar, o texto aborda a utilização da tecnologia como fonte do saber, apontando conexões com o domínio da matemática e com o desafio atrelado às habilidades de leitura de textos multimodais. Por fim, o artigo ressalta a importância do letramento tecnológico como parte do ensino da produção textual na educação básica, mostrando que, embora os jovens apresentem ter notório domínio das diversas tecnologias, muitos saberes precisam ser construídos para que eles sejam, de fato, letrados na era digital.

Palavras-chave: letramento escolar; letramento tecnológico; era digital.

\begin{abstract}
This article reflects on the scope of school and social literacy in the era of cyberculture. Composed of several sections, the discussions pervade the impact of digital technologies on the education of the reader, on the complexity and amplitude of literacy levels, as well as on reflections on the veracity of the multiple voices that speak on the Internet and in social networks. Closer to school work, the text addresses the
\end{abstract}


use of technology as a source of knowledge, pointing to connections with the field of mathematics and the challenge linked to the ability to read multimodal texts. Finally, the article emphasizes the importance of technological literacy as part of the teaching of textual production in basic education, showing that, although young people have a clear mastery of the various technologies, many knowledges need to be constructed so that they are, in fact, literate in the digital age.

Keywords: school literacy; technological literacy; digital age.

\section{Tecnologia e leitura: o fascínio da pluralidade}

A cibercultura nos impregna diariamente e, na sua velocidade alucinante, traz uma liquidez de palavras e de imagens. O constante movimento verificado na leitura em ambiente virtual nos remete ao caleidoscópio, antigo brinquedo infantil conhecido como 'olho mágico' que, por meio do reflexo da luz exterior em pequenos espelhos, causa combinações variadas e novos efeitos visuais ao girar os tubos: são diversas as imagens coloridas; um novo movimento, uma nova imagem.

A leitura mediada pela web proporciona perspectiva nova, multiplica as possibilidades de alcançar novas informações num ato de clicar um link e mais outro, assim sucessivamente. São novas vozes que nos permitem o acesso ao chamado multiletramento. As vantagens são inúmeras, contudo há que se ter cautela.

Este texto se propõe a refletir as vantagens e desvantagens do processo do letramento plural proporcionado pelas novas tecnologias. Após a implementação e a prática até abusiva da interação online, seja para o entretenimento, seja para a busca da informação, seja para o ensino e aprendizagem de saberes formais previstos no arsenal de conhecimentos que se querem adquiridos pelos aprendizes no letramento escolar, vale o alerta de educadores e pensadores de renome.

Ao receber o título de Doutor Honoris Causa em comunicação e cultura na Universidade de Turim, o filósofo e escritor Umberto Eco ${ }^{1}$ criticou o papel das novas

\footnotetext{
1 Umberto Eco nasceu na Alexandria em 5 de janeiro de 1932 e faleceu em Milão, no dia 19 de fevereiro de 2016. Foi um escritor, filósofo, semiólogo, linguista e bibliófilo italiano de fama internacional. Professor titular da cadeira de Semiótica e diretor da Escola Superior de ciências humanas na Universidade de Bolonha. Ensinou temporariamente em Yale, na Universidade Columbia, em Harvard, Collège de France e Universidade de Toronto. Colaborador em diversos periódicos acadêmicos, dentre eles colunista da revista semanal italiana L'Espresso, na qual escreveu sobre uma infinidade de temas.
} 
tecnologias no processo de disseminação da informação. Gerou uma polêmica mundial ao afirmar que as redes sociais dão o direito à palavra a uma "legião de imbecis" que antes falavam apenas "em um bar e depois de uma taça de vinho, sem prejudicar a coletividade"2. Com isso, nesse novo contexto social, considera-se importante que se faça uma nova reflexão a respeito do letramento digital com o auxílio das tecnologias.

O crescente uso das Tecnologias da Informação e Comunicação (TICs), a partir da década de 80, se deu de forma avassaladora. Desde então, os tecnófilos consideram somente aspectos positivos nesse "avanço" e os tecnófobos apontam enfaticamente para fatores destrutivos e submissos das TICs. Não precisamos de extremos para viver em sociedade, mas de equilíbrio, bom senso e consenso (MAIA, 2017).

A facilidade de acesso à internet e a hiperinformação podem gerar a banalização do conhecimento, bem como colocar leigos e profissionais mais próximos ao conteúdo informacional. A grande questão é a veracidade dos informes obtidos na internet que pode suscitar eficácia na educação, saúde, na ciência, enfim, no aumento de conhecimento aos que lançam mão de buscas na web.

Não há como negar que a velocidade e a quantidade de informações contidas na rede trazem enorme facilidade de acesso ao conhecimento e promovem a globalização de informações. Para Helman (2009:272), contudo, a globalização nunca é "unidirecional ou impossível de ser detida, havendo muitas formas diferentes de resistir à sua influência hegemônica sobre a vida do dia a dia". As forças locais, como as resistências culturais de determinada localidade, geram o que o autor denomina de "glocalização" (glocalization). Um bom exemplo é a medicina aiurvédica da Índia importada para a Alemanha que sutilmente tem sido modificada para se adequar às expectativas culturais locais alemães de cuidados médicos. Ainda assim, percebe-se

Eco foi, ainda, notório escritor de romances, entre os quais $O$ nome da rosa e $O$ pêndulo de Foucault. Junto com o escritor e roteirista Jean-Claude Carrière, lançou em 2010 "N'Espérez pas vous Débarrasser des Livres" ("Não Espere se Livrar dos Livros", publicado em Portugal com o título "A Obsessão do Fogo" no Brasil como "Não contem com o fim do livro"). Disponível em: https://pt.wikipedia.org/wiki/Umberto Eco. Data de acesso: 28/10/2017.

2 Durante o evento em 2015 o escritor afirmou que "normalmente, eles (os imbecis) eram imediatamente calados, mas agora eles têm o mesmo direito à palavra de um Prêmio Nobel". 
inegável influência da globalização na reconstrução de identidades pessoais, sociais e profissionais. "Mais do que definir globalização, é necessário observar os seus efeitos nas práticas escolares e curriculares e estudar de que modo influencia 0 pensamento curricular" (PACHECO \& PEREIRA, 2006).

Quase a metade dos brasileiros usa a internet regularmente, é o que mostra a Pesquisa Brasileira de Mídia 2015 (PBM 2015). A cada ano cresce o número de horas conectadas, diariamente, pelos brasileiros, evidenciando que o hábito de usar a internet está cada vez mais intenso. O percentual de pessoas que a utiliza todos os dias cresceu de 26\% na PBM 2014 para 37\% na PBM 2015 (BRASIL, 2014). Seja qual for a área da ciência (exatas, saúde, sociais), o uso da tecnologia desperta atenção em relação aos modos de utilização e aos efeitos no dia a dia das pessoas, assim como seu impacto na sociedade. Entre o emissor e o receptor da informação, há um risco a ser avaliado, pois nem todas as incertezas de hoje podem ser as de amanhã.

\section{Competências e níveis de letramento}

A informação existe e está disponível ao leitor, mas o grau de compreensão sobre aquilo que está escrito é muito importante, principalmente quando o assunto interfere diretamente no autocuidado à saúde. Não é apenas a decodificação de símbolos linguísticos e o reconhecimento das palavras que estruturam uma boa leitura. É preciso interpretar e compreender o sentido do texto:

Aprender a ler e a escrever é apropriar-se do código linguístico, é tornar-se um usuário da leitura e da escrita, com real compreensão dos usos e funções da linguagem que esteja sustentada em um real interesse em comunicar e compreender. Por meio da alfabetização, o homem pode tornar-se um ser global, simbólico, social, um cidadão inserido na civilização moderna, com o domínio de um dos mais significativos meios de comunicação humana (AZEVEDO, 2012:14).

Muitas vezes, "sujeitos com letramento nulo ou quase nulo só conseguem interpretar a informação se estão presentes dispositivos figurativos, imagens icônicas que os ajudem no processamento da leitura" (LEAL e MOLLICA, 2015).

Dentre os muitos tipos, ressaltamos a diferença entre o letramento social e escolar. O letramento social é condição que envolve "um conjunto de práticas sociais que usam a escrita, como sistema simbólico e enquanto tecnologia, para objetivos específicos" (KLEIMAN, 1995:18-9); o letramento escolar, por seu turno, é "o resultado da ação de ensinar e aprender a ler e a escrever" (SOARES, 1998:19), cuja meta é a de desenvolver "habilidades, conhecimentos e atitudes necessários ao uso efetivo e 
competente da leitura e escrita nas práticas sociais que envolvem a língua escrita" (SOARES, 2003:89).

O Indicador de Alfabetismo Funcional (INAF), obtido por meio de pesquisa realizada pelo Instituto Paulo Montenegro, em parceria com a Organização Não Governamental Ação Educativa, com o apoio do IBOPE Inteligência, mensura o nível de alfabetismo da população brasileira entre 15 e 64 anos. Avaliando o grau de domínio de suas habilidades e práticas de leitura, de escrita e de matemática aplicadas ao cotidiano, identificaram-se dois grupos: os analfabetos funcionais e os funcionalmente alfabetizados (IPM, 2016). De acordo com o $\mathrm{INAF}^{3}$, os analfabetos funcionais são, por sua vez, agrupados em: (1) Analfabeto, que corresponde à condição dos que não conseguem realizar tarefas simples, que envolvem a leitura de palavras e frases, ainda que uma parcela dessa população consiga ler números familiares (números de telefone, preços etc.); (2) Rudimentar, que equivale à capacidade de localizar uma informação explícita em textos curtos e familiares (como um anúncio ou um bilhete), ler e escrever números usuais e realizar operações simples, como manusear dinheiro para o pagamento de pequenas quantias ou fazer medidas de comprimento usando a fita métrica.

Os funcionalmente alfabetizados até 2011 eram distribuídos nos níveis Básico e Pleno. A partir de 2015, a escala Inaf aprimorou a interpretação dos resultados, classificando os respondentes em 3 níveis: (1) Elementar, que compreende as pessoas consideradas funcionalmente alfabetizadas, pois já leem e compreendem textos de média extensão, localizam informações mesmo que seja necessário realizar pequenas inferências, resolvem problemas envolvendo operações na ordem dos milhares, resolvem problemas envolvendo uma sequência simples de operações e compreendem gráficos ou tabelas simples em contextos usuais. Mostram, no entanto, limitações quando as operações requeridas apresentam maior número de elementos, etapas ou relações; (2) Intermediário, que abrange leitores capazes de localizar informações em diversos tipos de texto, resolvem problemas envolvendo percentagem ou proporções ou que requerem critérios de seleção de informações, elaboração e controle de etapas sucessivas. As pessoas classificadas nesse nível interpretam e elaboram sínteses de textos diversos e reconhecem figuras de linguagem; no entanto,

${ }^{3}$ http://www.ipm.org.br/inaf. Acessado em 02/02/18. 
têm dificuldades para perceber e opinar sobre o posicionamento do autor de um texto; (3) Proficientes, que constituem os aprendizes com habilidades que não mais lhes impõem restrições para compreender e interpretar textos em situações usuais: leem textos de maior complexidade, analisam e relacionam suas partes, comparam e avaliam informações e distinguem fato de opinião. Quanto à matemática, interpretam tabelas e gráficos com mais de duas variáveis, com elementos como escala, tendências e projeções.

Certamente o letramento escolar e o letramento social, embora situados em diferentes espaços e em diferentes tempos, são parte de um mesmo processo mais amplo. Mollica (1995:157) afirma que "os integrantes de certo grupo social mantêm marcas linguísticas compartilhadas, diferenciando-se em qualidade e/ou em quantidade dos de outros grupos sociais”. O grau de inserção à rede, a uma dada comunidade discursiva, condiciona o comportamento linguístico das pessoas: "quanto maior o nível de adesão ao grupo, maior é a garantia de o falante apresentar marcas linguísticas próprias à rede a que pertence".

Há uma nova alternativa de autonomia para a produção do conhecimento a partir da possibilidade de apropriação e de exploração dos conhecimentos produzidos em comum (GUIMARÃES, 2015). No letramento digital, o sujeito precisa de habilidades para construir sentidos com base em textos disponíveis na web, a partir de links e hiperlinks. Para isso, torna-se necessária maturidade que distingue o leitor iniciante do leitor maduro. Deve-se atentar ao que Pereira \& Pacheco (2006) consideram como modo de reconhecer a forma a partir da qual os conhecimentos são ensinados, assim como os conteúdos e sua avaliação.

\section{Construção do conhecimento sobre Saúde na era tecnológica}

A tecnologia é sempre evolutiva, só anda para frente e não tem como ignorála. Mesmo que essa evolução venha impregnada de um apelo capitalista, quem não a acompanha não recicla, não inova. No ambiente educacional, a tecnologia pode ser ferramenta poderosa no processo de aprendizagem.

A história recente da relação entre as TIC e a Educação mostra a existência de um grande desequilíbrio em comparação a outros setores da sociedade. Apesar de algumas escolas de renome se esforçarem para manter a prioridade de adoção das novas tecnologias, em geral o sistema educacional, especialmente o público, demora a obter as vantagens oferecidas pelas novas TIC, seja pela falta de recursos, seja pela resistência dos protagonistas, enfim, as iniciativas de sucesso pareceram sempre ancoradas na ousadia, na perseverança e até na 
obstinação de gestores ou docentes, para que pudessem ter sido colocadas em prática (GOULART, 2014:12).

Nas escolas, há tempos se questiona o modelo estrutural de transmissão de conhecimento verticalizado, hierarquizado, a partir do qual o saber soberano do professor é transmitido para o aluno que precisa aprender e memorizar o que lhe é ensinado. Na vida, em meio às interações sociais, as relações passaram a ser em redes colaborativas. O uso da tecnologia na educação não substitui o lugar do professor, mas modifica sua posição no processo pedagógico. Sua atuação se solidifica na estimulação por uma curiosidade científica e pelo papel de destaque como mediador da informação.

Helman (2009:79) considera que as "sociedades urbanizadas modernas, ocidentais ou não, são mais propensas a exibir pluralismo nos cuidados de saúde". Sendo assim, o desenvolvimento da internet e da World Wide Web (www) solidificou a base da nova estrutura relacional dentro da sociedade em rede. Web (aplicação de compartilhamento de informações de grande alcance global executado na internet) e internet (rede mundial de computadores) "não são palavras sinônimas, mas possuem estreita relação entre si"; oferecem aos indivíduos "ferramentas de comunicação que levam ao questionamento de muitos paradigmas" (GONÇALVES, 2015:185).

Acessar a internet e obter informações sobre saúde, por exemplo, é uma das razões mais comuns para se conectar (HELMAN, 2009:297). A busca de conteúdos sobre saúde constitui realidade crescente, seja para procurar informações em relação a problemas específicos, para fins de esclarecimento com profissionais, seja para permitir a comunicação entre as pessoas que apresentam similar condição. As fontes virtuais de informação em relação à saúde são muito variadas. A curiosidade sobre técnicas modernas, principalmente as relacionadas à estética, despertam permanente interesse do público leitor. Além de enunciados que se mantêm mesmo sem sustentação científica, a internet traz, ainda, à tona um apelo visual com reações intersubjetivas.

A busca pelo dente extremamente branco e perfeito, por exemplo, seja por clareamento, seja por lentes de contatos dentais, tem o apelo de imagens que constroem um desejo intersubjetivo, principalmente por meio de pessoas famosas (Figura 1). Porém, há uma fragilidade na proposta das imagens, uma vez que fotos e figuras são manipuláveis tecnologicamente (Figura 2). 

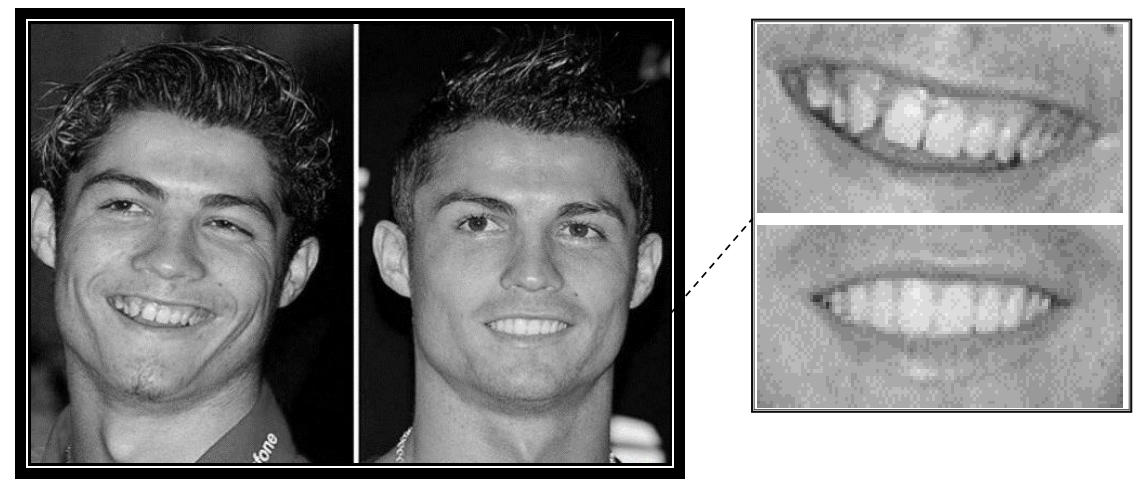

Fig. 1

Fonte:Google

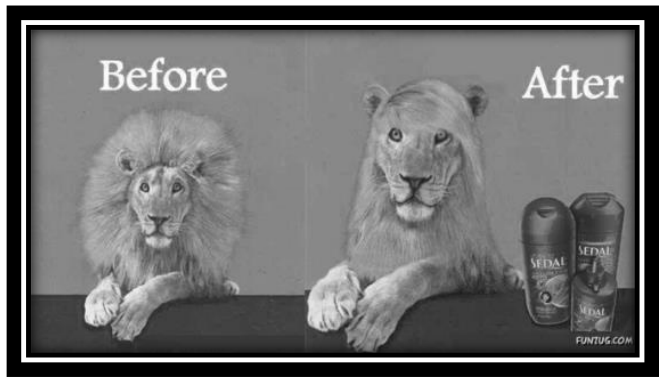

Fig. 2

Fonte: Funzug imagens; Google imagens

Na odontologia, tem-se observado que a busca de informações na internet pode interferir no conhecimento dos pacientes sobre determinados assuntos. Algumas crenças e pré-conceitos estabelecidos pelo senso comum, porém, não são desconstruídos por essas informações. De olho nas falsas promessas, principalmente nas que despertam tipos físicos fora da realidade, na França, desde o dia $1^{\circ}$ de outubro de 2015, há uma lei que obriga avisar os leitores sobre o uso de programas (photoshop) em imagens de modelos, aplicados em qualquer tipo de publicação.

Neste cenário atual de processo de socialização entre as pessoas, o uso da linguagem é fator decisivo para o entendimento. Sendo assim, considera-se que linguagem, argumentação e racionalidade são processos interligados. É na vida que os sujeitos, falantes e ouvintes, em suas práticas comunicativas, têm como finalidade chegar ao entendimento. Na argumentação por meio da linguagem, os sujeitos oferecem razões para a elucidação de pretensões de validade, cuja comprovação 
explícita demanda a forma de comunicação que cumpre os pressupostos da argumentação.

Em 2010, um estudo de Pletneva et al, realizado pela Health On the Net Foundation (HON) com 524 pessoas (profissionais da saúde e leigos), evidenciou que a qualidade da informação em saúde é a principal dificuldade para a pesquisa na internet. Para aumentar a qualidade das informações online sobre saúde, os fatores mais considerados seriam a "confiabilidade/credibilidade, precisão, disponibilidade da informação e facilidade de busca de informações e navegação". Portanto, na atual sociedade midiática, conectada full time, os indivíduos fazem interpretações por si mesmos das informações contidas na rede, sendo estimulados, inclusive, a uma obediência mediada pelas informações recebidas (SILVA, 2013). Gonçalves e Lima (2014:921) afirmam que "as atuais dinâmicas comunicacionais mudam a forma de validação da informação, pois é possível visualizar e discutir essa dinâmica, uma vez que prevalece a autoridade do argumento e não o argumento da autoridade". Para os autores, "essas mudanças são parte de processos na esfera cultural que variam de acordo com a época em que se vive e das tecnologias disponíveis em cada sociedade".

A pessoa, a sociedade e a cultura são os componentes estruturais do mundo, onde os sujeitos passam a entender a experiência vivida por meio da prática, por meio de discurso centrado nos aspectos significativos de suas vivências. Os conhecimentos e as práticas adquiridas ao longo da trajetória de vida dos sujeitos "se evidenciam em um movimento dialético de desconstrução e reconstrução, ganhando direcionalidade e força" (OLIVEIRA, 2011). Eis o lócus em que se processa o agir social, em que cada pessoa tem seus interesses e a única forma de organizá-lo é via interação social. Assim, o ser humano se desenvolve em torno de três dialéticas: o uso da linguagem, a dialética da interação e a dialética do trabalho. 
A conectividade nos leva a respostas imediatas, ao "just in time", ao "groupware"5 e tantas outras facilidades momentâneas de comunicação (MORAN, 1995). As dúvidas sobre saúde podem ser buscadas na internet, nos programas de rádio ou televisão, mas sempre veiculam conhecimento ou saciam a curiosidade fugaz.

\section{Um retrato da Matemática}

QUERIDA MATEMATICA ESTOU CANSADO DE

TENTAR ENCONTRAR O

SEU X, ACEITE O FATO DE QUE ELE SE FOI.

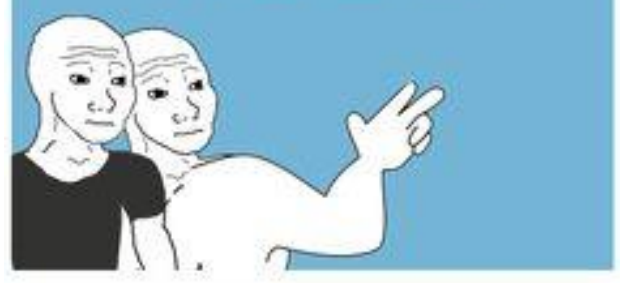

O ensino-aprendizagem da matemática fica enriquecido quando the são incorporadas as Novas Tecnologias. Hoje contamos com auxílio de softwares robustos, por meio de fácil manuseio e de uso livre, que subsidiam os alunos a desenvolverem habilidades capazes de contribuir para o aprendizado, por exemplo, da geométrica, do cálculo. Também podem estar presentes, nas salas de aula, recursos livres encontrados no Youtube, em páginas de professores de matemática, bastando que o aluno utilize o Google para fazer sua pesquisa. Todos os recursos são importantes e válidos, desde que haja adequada orientação para a escolha do material a ser usado. Sabemos que a internet aceita e comporta qualquer tipo de informação. Cabe à escola a tarefa de recomendar e selecionar sites adequados ao conteúdo a ser trabalhado em determinado ano escolar e em dada faixa etária do discente. Num mundo de tantas possibilidades, por que continuamos, em matemática, a amargar os piores resultados?

Em relação à edição anterior da pesquisa (2012), o desempenho em Ciências e leitura ficou estagnado e, em Matemática, a nota final foi a de 11 pontos menor - piora considerada estatisticamente relevante. No ranking que considera todos os países, a melhor posição do País é em leitura - 59.․ Em Ciências, o ensino brasileiro ficou na 63. ํㅗ posição. Mas foi em Matemática o pior resultado, a 65. ${ }^{a}$ colocação, "ganhando" apenas de Macedônia, Tunísia, Kosovo, Argélia e República Dominicana.

\footnotetext{
4 Just In Time é um sistema de administração da produção que determina que tudo deve ser produzido, transportado ou comprado na hora exata. Pode ser aplicado em qualquer organização, para reduzir estoques e os custos decorrentes. Wikipédia Disponível em: https://pt.wikipedia.org/wiki/Just_in_time Data do acesso: 03/10/17

${ }^{5}$ Software colaborativo (ou groupware) é um software que apoia o trabalho em grupo, coletivamente. Skip Ellis o definiu como um "sistema baseado em computador que auxilia grupos de pessoas envolvidas em tarefas comuns (ou objetivos) e que provê interface para um ambiente compartilhado". Disponível em: https://pt.wikipedia.org/wiki/Software_colaborativo Data do acesso: 03/10/17
} 
Fonte: http://educacao.estadao.com.br, acesso em 19/11/17, data da publicação em 06/12/16.

De fato, a internet garantiu o seu lugar na vida cotidiana e na escolar. Não podemos negar sua importância como ferramenta de aprendizagem. As escolas particulares, em sua maioria, fazem uso das Novas Tecnologias em suas salas de aulas. Para tanto, reestruturam suas instalações, instrumentalizam os professores e estimulam seus alunos. Grupos de estudo são criados e os alunos, cada vez mais cedo, incorporam o universo digital, um diferencial na trajetória profissional. Além disso, a escola fica mais próxima da realidade, já que é ampla a utilização da web em casa, com amigos e no meio social.

$\mathrm{Na}$ tentativa de diminuir o abismo na formação do aluno da rede pública e privada, alguns Projetos Pilotos envolvendo as TICs foram criados pelo MEC Ministério de Educação e Cultura. Entre eles podemos citar o Projeto UCA - Um Computador por Aluno, que contou com a participação de algumas escolas selecionadas nos Estados. No Rio de Janeiro, a implementação total do Projeto quase não aconteceu. Problemas como o aumento de carga elétrica nas escolas para o recarregamento dos computadores, a instalação da rede WIFI, a ausência de profissionais para suporte e manutenção das redes, o sistema operacional escolhido, a dificuldade dos professores com o uso de um sistema operacional diferente do Windows e o atraso nas Formações Continuadas, entre outros, contribuíram para que o Projeto não alcançasse os objetivos propostos. E os alunos? Entusiasmadíssimos com o uso do computador nas aulas e decepcionados com a precariedade da instalação e utilização.

Hoje, dificilmente um adolescente não participa das redes sociais. O manuseio das mídias digitais é muitas vezes transmitido "boca a boca". O aprendizado incidental permite que os jovens façam download, naveguem na internet, se comuniquem, façam compras, se utilizem ao máximo de opções de navegação dos seus celulares. Por que, então, os mesmos adolescentes não utilizam a web para ajudar nos estudos? Certamente a resposta não é única. Uma delas pode ser o desconhecimento das possibilidades dos celulares. Se considerarmos essa uma das possíveis respostas, a escola pode ser entendida como uma das soluções, talvez a mais simples.

Na Matemática, são muitos os recursos. Destaque-se o uso de sites diversos e do Meme, termo grego que significa imitação. O meme é amplamente utilizado no 
mundo virtual e se refere ao fenômeno de "viralização" de uma informação, no "boca a boca" virtual, que se espalha rapidamente por meio de mensagens curtas com grande apelo visual e de humor (quase sempre). Como gênero promissor em sala de aula (cf. Barreto, 2015), o meme pode ser o início de um caminho que mostre aos alunos que a internet deve estar presente na vida escolar.

\section{A era dos aplicativos: tecnologia $X$ pós-verdade}

As mudanças tecnológicas fortalecem as trocas informacionais, mas fragilizam as interações relacionais. A qualidade e a veracidade das informações assumem papel central no cenário social. O dicionário Oxford, por exemplo, escolheu a palavra pós-verdade como o vocábulo do ano de 2017, "por ser um adjetivo que lida com circunstâncias em que fatos objetivos são menos influentes em moldar a opinião pública do que o apelo a emoções e crenças pessoais" ${ }^{6}$.

A criação e utilização de aplicativos (App) é a realidade concreta de como a tecnologia pode ser útil no cotidiano das pessoas. No campo profissional também em curso está seu amplo crescimento e utilização. Entre os mais recentes, há o aplicativo criado pela Subsecretaria de Educação, Valorização e Prevenção para orientar policiais e guardas municipais a respeito de como deve ser o tratamento às vítimas de crimes associados a um tipo de constrangimento, como intolerância religiosa e homofobia. Também existem os aplicativos de monitoramento da saúde, como o que está sendo desenvolvido por uma empresa, para lançamento em 2018, cujos níveis de estresse, ansiedade e horas de sono são monitorados pelo mecanismo de machine learning (ou aprendizado de máquina) do app.

O deslocamento da responsabilização do cuidado à saúde deve ser amplamente discutido. A mudança do locus traz não só o empowerment (poder) individual, mas o

\footnotetext{
${ }^{6}$ O Dicionário Oxford dedica sua palavra do ano, 'pós-verdade', a Trump e Brexit. Esta é a palavra do ano para o Dicionário Oxford, que constatou que o seu uso cresceu no "contexto do referendo britânico sobre a União Europeia e nas eleições presidenciais dos Estados Unidos”, até converter-se em um termo comum nas análises políticas. Segundo o Oxford, o termo foi utilizado pela primeira vez em um artigo de Steve Tsich, publicado em 1992 na revista The Nation, no qual ele falava sobre a primeira Guerra do Golfo. Tsich lamentava que "nós, como povo livre, decidimos livremente que queremos viver em uma espécie de mundo da pós-verdade", ou seja, um mundo no qual a verdade não é mais tão importante ou relevante. Disponível em: https://brasil.elpais.com/brasil/2016/11/16/internacional/1479308638 931299.html Data do acesso: 20/10/2017
} 
esvaziamento da responsabilidade pelo Estado, pelas seguradoras, pelos planos de saúde. Cabe a pergunta: o monitoramento substitui o acompanhamento profissional?

Pesquisas mostram que profissões como a de advogado correm risco. De acordo com Maurício Gieseler 7 , "Administradores dos maiores escritórios de advocacia dos Estados Unidos preveem que em 10 anos as máquinas irão substituir os advogados com até um ano de carteira e os paralegais". Por meio do programa de computador Ross, desenvolvido por universitários de Toronto, pertencente ao computador cognitivo da IBM, é possível tirar dúvidas acerca de questões jurídicas. Ao ser lançada a pergunta, o programa faz uma pesquisa a leis e até mesmo a casos similares já julgados para emitir uma resposta. Gieseler aposta no desenvolvimento próximo de um sistema de inteligência artificial. O que atualmente funciona como uma "plataforma de consulta com a possibilidade de um refinamento em seu trabalho por conta de suas características cognitivas", em breve, passará a exercer a função de magistrados. No Brasil, já existem aplicativos de assessoria jurídica que auxiliam o consumidor em problemas como com compras na Black Friday, na web, com contratação de planos de saúde, por exemplo. A partir de consulta gratuita, caso o cliente julgue necessário, pode contratar os serviços de um advogado por meio do app.

\section{A multimodalidade textual e o ensino}

Fato é que a vida mudou e as formas de comunicação e de relacionamento, assim como as possibilidades de se interpretar o mundo já não são mais as mesmas de tempos atrás. No entanto, a escola pública se encontra estacionada em séculos passados. O modelo educacional que temos hoje no Brasil é o mesmo do século XIX. Computadores, internet, data shows foram disponibilizados à escola, mas a metodologia educacional continua a mesma; o que antes o professor escrevia na lousa, agora apresenta em formato de slides. Não saímos, ainda, da perspectiva do cumprimento do conteúdo. De que modo estamos preparando o indivíduo para as práticas socioculturais?

\footnotetext{
${ }^{7}$ http://blogexamedeordem.com.br/futuro-da-advocacia-computador-que-substitui-o-trabalho-dosadvogados-ja-esta-na-ativa/
} 
É de extrema importância que o aluno do século XXI seja capaz de dar conta da leitura não linear, de textos multimodais, de hiperlinks que estão o tempo todo ao seu redor, para não dizer em suas mãos com seus smartphones.

A sociedade na qual estamos inseridos se constitui como um grande ambiente multimodal, no qual palavras, imagens, sons, cores, músicas, aromas, movimentos variados, texturas, formas diversas se combinam e estruturam um grande mosaico multissemiótico. (DIONISIO; VASCONCELOS, 2013:19)

Assim, a leitura não linear vai abrindo links da mesma forma quando acessamos sites de busca que nos conduzem a outras janelas, como um "olho mágico" que vai formando mosaicos e, conforme o giramos, vamos tendo acesso a novos formatos e cores.

O texto, por conseguinte, deve ser trabalhado nas salas de aula sob o prisma que defende Marcuschi (2008:80), "construído numa interação multissistemas". Considerando que todo texto constitui um processo semiótico e multimodal, pois uma palavra em negrito, ou grafada em letras maiúsculas, assim como em textos orais, uma entonação diferente produz sentido. $O$ utente necessita adquirir a competência digital não somente de ler, mas também de produzir textos em diversificados gêneros e suportes. Devemos ir além. As faculdades multimodais devem ser utilizadas no processo de ensino como instrumento facilitador da aprendizagem, como já defendem alguns estudos na área da cognição e da psicolinguística.

Com o intuito de mostrar na prática como se podem trabalhar textos multimodais na sala de aula, apresentamos a seguir algumas atividades. Destaque-se o trabalho simultâneo que vem sendo defendido por Leal e Mollica (2006, 2009, 2010, 2012), segundo o qual, nas séries iniciais, deve-se associar o Português com a Matemática.

Proposta I - Leia o meme:

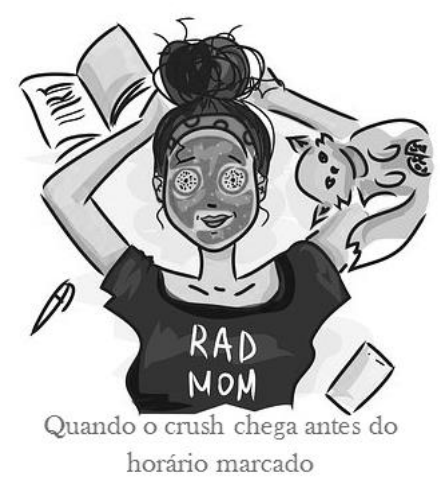


1. Baseando-se no seu conhecimento de mundo e no texto acima, responda: $O$ que significa crush?

2. Que elementos visuais do texto ajudam a entender o significado que assume, em Português, a palavra inglesa crush?

3. A conjunção que inicia o texto verbal expressa ideia de

4. De que maneira o emprego dessa conjunção estabelece significado entre a frase e a imagem?

5. Que elementos da parte não verbal do texto comprovam que o crush chegou antes do horário marcado.

6. Como você já deve ter percebido, os memes constituem um novo gênero textual composto sempre por linguagem verbal e não verbal. Se a imagem fosse retirada, ficando apenas a frase escrita, o efeito de sentido seria 0 mesmo? Comente.

7. Se o crush chegasse na hora marcada, como você idealizaria o meme? E se chegasse 2 horas após a hora marcada?

O principal objetivo da Proposta I de atividade é conduzir o aluno à relação entre os elementos linguísticos que compõem a linguagem verbal e os componentes que constituem a linguagem não verbal. Além disso, o exercício valoriza o conhecimento trazido pelo aprendiz ao pedir que seja identificado o sentido da palavra crush, gíria utilizada na atualidade pelos adolescentes, que significa "paquera", "aquele por quem se tem uma queda", o que possibilita, ainda, ao professor falar a respeito de empréstimo e estrangeirismo, de acordo com 0 ano de escolaridade em que o exercício seja aplicado.

Proposta II - Observe a imagem e responda: 


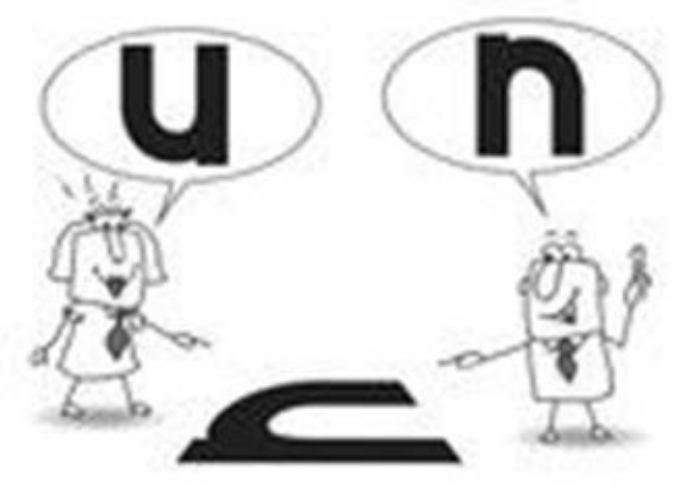

1. A imagem acima simula um diálogo. Quem são os interlocutores que compõem o ato comunicativo?

2. Levando em consideração as expressões faciais, as personagens parecem divergir uma da outra? Comente.

3. Baseando-se nos balões e no desenho central, responda: Os interlocutores parecem dizer a mesma coisa ou coisas opostas? Explique.

4. Você já se viu em uma situação comunicativa parecida com essa? Conte-nos como foi.

5. Pode-se, portanto, afirmar que o receptor sempre entende o que o emissor quis de fato dizer? Justifique.

6. O mesmo ocorreria se fossem considerados os números 6 e 9 no lugar das letras u e n

A proposta II sugere exercícios que trabalhem com os elementos da comunicação, considerando os constituintes não verbais na produção de sentidos do texto, e conduzem o educando à reflexão sobre o ato comunicativo.

Proposta III - Observe o texto a seguir e responda às questões a ele propostas:

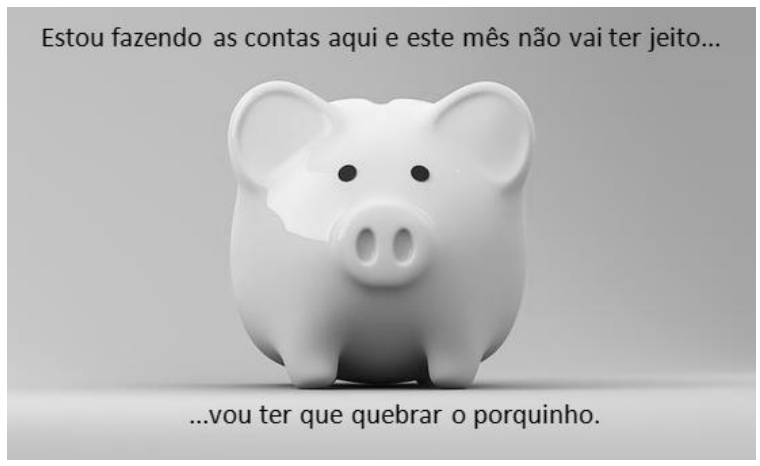

1. Qual o sentido da expressão "quebrar o porquinho" no texto acima? 
2. Qual relação de sentido se pode estabelecer entre "fazer as contas" e "quebrar o porquinho"?

3. Associe o emprego do substantivo diminutivo "porquinho" à imagem central do texto.

4. De que maneira a imagem contribui para a construção de sentido do texto?

$\mathrm{Na}$ proposta III, oferecemos questões que conjugam imagem e frase na produção de sentidos do meme, além de explorar o valor semântico de expressões linguísticas próprias de situações informais de uso do português brasileiro (PB). Esse mesmo meme pode ser utilizado no trabalho com a Educação Financeira.

Proposta IV - Observe o meme e responda às questões propostas na sequência:

Aì é que está o X da questão

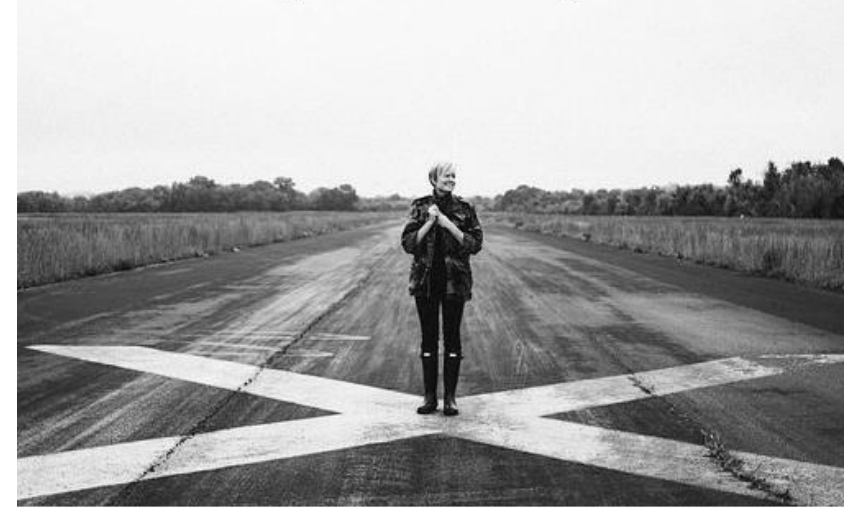

1. Correlacione a frase verbal à imagem do texto acima.

2. Encontre na parte verbal do texto evidências da língua oral.

3. Pode-se afirmar que marcas de oralidade são apropriadas a esse gênero textual?

4. De acordo com seu conhecimento de mundo, que concepção você tem da expressão "X da questão"?

Em conformidade com objetivos deste artigo, o exercíco IV propõe atividades de leitura não linear de texto multimodal, envolvendo a expressão linguística que se apropria da matemática "x da questão". Segundo o dicionário informal ${ }^{8}$, "x da questão" "é uma expressão usada para selecionar, enfatizar ou ressaltar alternativas, tanto em teste e questionários como em situações comparativas. É a única alternativa correta entre incorretas ou parcialmente corretas. Também usada para ressaltar a importância

${ }^{8}$ (http://www.dicionarioinformal.com.br/significado/x\%20da\%20quest\%C3\%A3o/609/) 
de um fato". Podemos, também, associá-la às equações matemáticas em que encontramos o valor de $\mathrm{x}$.

Proposta V - Com base no texto que se segue, responda aos exercícios apresentados:

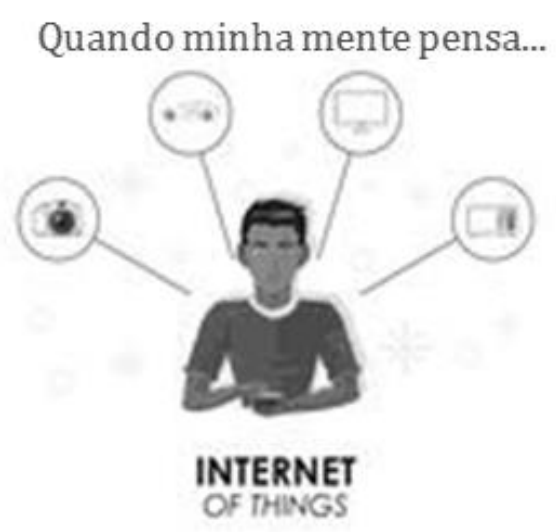

...em $n$ coisas ao mesmo tempo.

1. Baseando-se na parte visual do meme, o que lhe parece significar a expressão " $n$ coisas"?

2. Podemos afirmar que $n=4$ ?

3. Qual a relação de sentido existente entre " $n$ coisas" e os balões em volta da cabeça do rapaz da imagem?

4. Se a imagem fosse retirada e mantivéssemos apenas o texto verbal, o efeito de sentido do texto seria o mesmo? Justifique.

Os exercícios da Proposta $\mathrm{V}$ procuram unir os saberes linguísticos aos matemáticos. A letra $n$ representa o enésimo número, aquele que não foi alcançado, ou seja, número que não se conhece, daí a expressão " $n$ coisas" significar tantas coisas que não se pode contar. Ademais, as atividades estimulam o raciocínio lógicointerpretativo do aluno ao Ihe exigir reflexões por meio da leitura não linear de texto multimodal.

Proposta VI - Atente para o texto a seguir: 


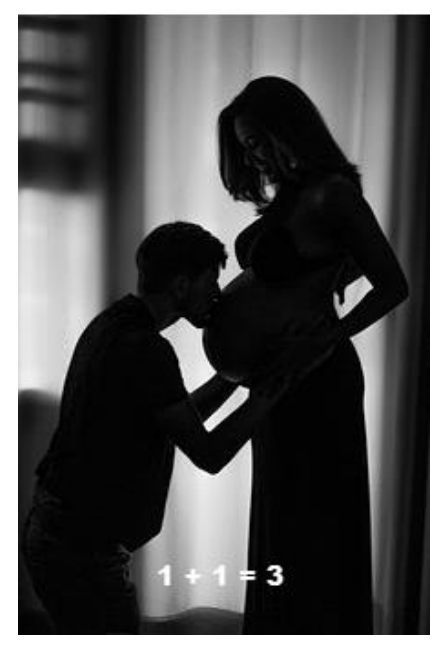

Agora, responda:

1. Que elementos compõem a imagem do texto?

2. Na parte inferior do texto, há a expressão matemática "1 + $1=3$ ".

a) De acordo com os cálculos matemáticos, pode-se dizer que a conta está correta? Explique.

b) O que justifica, no texto, o resultado da soma?

3. Se a imagem fosse retirada, a expressão matemática faria sentido? Justifique.

A proposta $\mathrm{VI}$ objetiva conciliar alguns conhecimentos básicos da matemática com elementos textuais não verbais na interpretação do texto.

Proposta VII - Observe a figura:

Agora, responda:

1. Que

elementos texto?

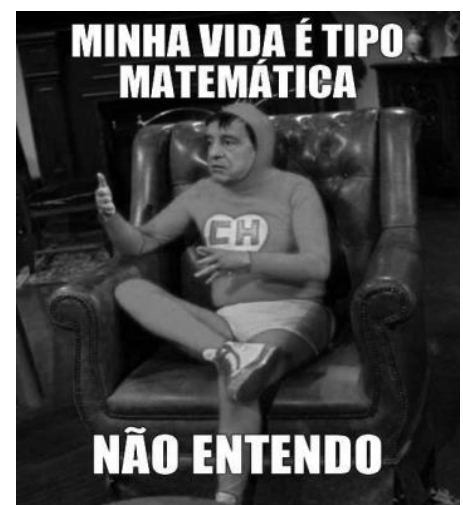

compõem a imagem do

2. Com base na imagem, quem seria o suposto interlocutor que se encontra subentendido?

3. Na parte verbal do texto, há uma expressão própria da linguagem coloquial.

a) Identifique-a.

b) Essa expressão lingüística se encontra adequada ao gênero textual? 
4. Se a imagem fosse retirada, o efeito de sentido seria o mesmo? Justifique.

5. Na sua opinião, o texto aponta para algum tipo de preconceito? Qual?

A Proposta VII levanta uma discussão sobre preconceito a respeito da natureza da Matemática, além de trabalhar aspectos linguísticos relacionados ao meme, enquanto gênero textual, frequentemente lido e criado por adolescentes e jovens em ambiente virtual.

\section{Leitura e produção textual no ciberespaço}

Com o amplo acesso à internet, nos tempos atuais, os jovens, de modo geral, se comunicam por aplicativos de mensagens (facebook, whatsapp, entre outros). Tratase de um contexto altamente favorecedor de práticas de leitura e produção textual, ainda que de maneira informal e com recursos linguísticos adequados às essas ferramentas, que exigem padrões mais simplificados da gramática para atender a uma interação que, embora virtual, é tão momentânea e online como as atividades comunicativas face a face.

O domínio dos distintos aparatos tecnológicos não parece desafiador para uma geração que nasceu imersa no mundo digital. É impressionante como crianças e jovens lidam com dispositivos digitais (celulares e computadores), aplicativos e várias outras ferramentas disponíveis pela tecnologia moderna. A frequência de utilização de aparelhos móveis nos leva a supor que a nova geração não possui qualquer restrição de lidar com regras e mecanismos de produção-recepção dos textos: passam o dia digitando e lendo na tela do computador e do celular principalmente, interagindo com seus pares, focados em jogos. Permanece, porém, a pergunta: até que ponto essa população é capaz de explorar recursos das ferramentas digitais para atender a circunstâncias de produção e circulação de textos em esferas mais formais de comunicação? Para além de enviar e receber mensagens em conversas virtuais linguisticamente não monitoradas, os jovens possuem 'livre' acesso ao que circula nas redes sociais, nos jornais online, nos blogs e em centenas de outros sites onde são veiculados diversos tipos e gêneros textuais. As pesquisas sobre as vantagem e desvantagens do mundo virtual para a construção dos saberes formais e da escrita padrão não estão suficientemente desenvolvidas. Eis uma boa agenda de investigação. 
A atividade de ler nunca pareceu tão profícua com o advento e o fácil acesso aos conteúdos digitais. A famosa relação quem lê muito escreve bem pode, agora, ser testada com maestria. Iliovtiz (2008) questiona se essa relação, de fato, é biunívoca. A autora argumenta que, em alguns casos, a alta frequência de leitura não acarreta técnicas mais apuradas de escrita. No estudo desenvolvido, há casos de informantes que, mesmo com hábito frequente de leitura de revistas, jornais e textos de cunho literário, apresentaram produção escrita marcada por sentenças truncadas e pelo emprego insuficiente de sinais de pontuação para guiar uma leitura mais coerente e uma interpretação mais precisa. Houve ainda casos de informantes cujo hábito de ler não é tão contínuo, em comparação ao domínio de escrita bastante satisfatório.

Parece, então, que estamos diante de certa independência entre as técnicas de leitura e escrita. Ninguém ousaria questionar que a atividade de ler é crucial para a expansão do nosso repertório lexical, bem como para a de construções sintáticas e padrões linguísticos. Todo o inventário de tarefas de leitura e escrita é bastante variado, dada a natureza das circunstâncias envolvidas no evento comunicativo e as pressões do discurso, para atender às necessidades de interlocução, previstas pelo jogo enunciativo. Mas o hábito da leitura, por si só, não garante o acesso direto e transparente aos padrões canônicos afetos ao domínio de um leitor proficiente nem a todas as técnicas de escrita. Os procedimentos praticados na escola são dificilmente ancorados, de forma direta, no processo de construção de sentidos resultante da atividade de produção e recepção dos textos.

Destacamos, portanto, a importância do domínio do letramento digital como forma de aprimorar as habilidades que os jovens têm com as novas tecnologias em favor de tornarem-se capacitados a aplicar diversos recursos, voltados para técnicas de escrita em ambientes virtuais, com a exigência própria dos diferentes contextos comunicativos. Há, entretanto, certo descompasso entre a atividade de leitura e o domínio de técnicas de escrita disponibilizadas pelas ferramentas tecnológicas, em especial daquelas cuja produção textual requer atender a exigências de circunstâncias mais formais de uso da língua.

Soares (2002:145) chama a atenção para o fato de que os letramentos envolvem a capacidade do indivíduo de ser competente em eventos sociais de leitura e escrita: 
O estado ou condição de indivíduos ou de grupos sociais de sociedades letradas que exercem efetivamente as práticas sociais de leitura e de escrita, participarem competentemente de eventos de letramento.

A UNESCO $(2011: 2)^{9}$, por sua vez, sobre letramento digital, assevera que:

Digital literacy is an umbrella concept for important skill clusters whose names are often used as synonyms; their content, however, is no exactly the same. ICT literacy refers to a set of user skills that enable active participation in a society where services and cultural offerings are computersupported and distributed on the internet. Technological literacy (previously called computer literacy) entails a deeper understanding of digital technology and comprises both user and technical computing skills. Information literacy focuses on one of the key aspects of our Knowledge Society: the ability to locate, identify, retrieve, process and use digital information optimally.

Estreitando nossa visão para as técnicas de escrita, não é possível dissociar os diferentes conceitos. Práticas de letramento estão inseridas no conhecimento de letramento digital e tecnológico. Produções textuais em ambiente digital, ou dele decorrentes, desprovidas de mecanismos de formatação, de aplicação correta e adequada de caracteres especiais e de outros vários recursos disponíveis em práticas sociais de letramento que privilegiam esses e outros aspectos em paralelo com o conteúdo a ser informado, podem sofrer ruídos comunicativos importantes e, portanto, tal letramento tecnológico não pode estar alheio ao conhecimento do produtor.

A educação, em especial o ensino de língua materna quanto à prática de produção textual, precisa incorporar a noção de letramento tecnológico, inserindo o domínio dos recursos digitais empregados nas técnicas de escrita como parte da atividade básica proposta nos manuais instrucionais. Trata-se de um desafio que, como diz Xavier (2007:134-135):

(...) letrar digitalmente uma nova geração de aprendizes, crianças e adolescentes que estão crescendo e vivenciando os avanços das tecnologias de informação e comunicação. (...) ser letrado digital pressupõe assumir mudanças no modo de ler e escrever os códigos e sinais verbais e não verbais (...).

A tecnologia transporta o aprendiz para um mundo em que as formas de ler e escrever se atualizam a cada link acionado. Muitas vezes entendidos como simples conjuntos de nós e links aleatoriamente conectados, os hipertextos são permeados de efeitos linguísticos e pragmáticos, de design e de usabilidade, cuidadosamente pensados para atrair o público-alvo e atender às demandas do ato comunicativo (COSCARELLI, 2005:110). As técnicas de produção e recepção textuais são

9 Disponível em: http://unesdoc.unesco.org/images/0021/002144/214485e.pdf. Acessado em: 22/11/2017. 
maximamente diversas no ambiente digital e, da maneira como ocorre no mundo offline, as adequações às circunstâncias discursivas não são, nem um pouco, desgastadas. Uma notícia de jornal online nunca aparece com linguagem de aplicativos, como uma conversa no whatsapp, devido ao acordo tácito dos interlocutores com relação ao tipo de evento comunicativo.

Os textos que circulam na web, rede imbricada de nós e links, ou decorrem de um aparato tecnológico ou são produzidos com recursos vários de editores de textos, que thes imprimem novas formas e composições. Tais estratégias não são simplesmente técnicas alheias às atividades tradicionais de produção textual no âmbito escolar. O papel, como veículo de informação, quase não recebe mais impressões do punho, pois já é confeccionado para receber da tinta (ou cartuchos) o design produzido pelo mecanismo tecnológico. Tanto a leitura quanto a produção textual no ciberespaço não dispensam o conhecimento funcional e crítico da tecnologia e de seus mecanismos (FREITAS, 2010:338). O que houve, de fato, foi uma ampliação de formas de interação e de discursos, porém não livres das regras situacionais de comunicação.

Ressalta-se que a maioria das abordagens em torno do letramento digital focaliza o âmbito de técnicas e práticas de leitura, notadamente os trabalhos sobre hipertextos (LANDOW, 1992; MARCUSCHI \& XAVIER, 2004). As técnicas de produção associadas ao letramento tecnológico ainda não fazem parte da agenda acadêmica e, em consequência, do trato pedagógico na educação básica (BARTON \&LEE, 2015).

Dados extraídos da plataforma de experimentos com interações e produções textuais de discentes da educação básica - o Sabere - desenvolvido por Batista e Mollica (2014), revelam pouco ou nenhum conhecimento dos recursos disponíveis no editor de texto da ferramenta. A maioria dos estudantes demonstra não possuir conhecimento de combinações de teclas para acentuar palavras, aplicar pontuação aos textos, inserir caracteres especiais. Não se tem também verificada a exploração de ferramentas para formatação apropriada da produção, como fonte, cor, alinhamento, espaçamento e alternativas outras, como negrito, itálico. As produções a seguir, sobre a temática 'jogos eletrônicos', confirmam que os aprendizes ignoram técnicas previstas pelo letramento tecnológico. Além de erros ortográficos e 
gramaticais, os trechos em (1) e (2) não revelam domínio dos recursos da escrita em ambiente virtual:

(1) Jogos

Muitas pessoas e jovens jogão jogos com cenas inproprias violentas. Mas tem aquelas pessoas que jogão jogos sem violencia mas na minha opinião

cada um tem seu jeito de escolher o tipo de jogo. (All, I. 93-95)

(2) O DONO DO JOGO VIOLENTO. SE VOCE VICIA NO JOGO PODE CALZARCERIOS DANOS TIPO RISCO A SAUDE TIPO SAUDE FISICA E MENTAU E SEU FILHO PORISO VOCE DEVE LEVAR O CEL FILHO AU MEDICA. (AII, I. 60-62)

Cabe, pois, defender que o letramento tecnológico não deve mais estar à margem das atividades pedagógicas voltadas para a produção textual. As técnicas de leitura e de escrita perpassam pelo domínio das funcionalidades de planejamento e de editores de texto e, principalmente, de uma análise crítica dos recursos em relação às atividades sociais de letramento. A frequência de leitura não necessariamente automatiza as habilidades de escrita. Há técnicas de produção que se desenvolvem e amadurecem com exercícios frequentes e contínuos de escrita de textos.

Com efeito, o amplo acesso aos conteúdos digitais não assegura que os usuários se apropriem de técnicas de produção com as quais interagem na construção de sentidos. A destreza nos ambientes on-line e off-line exige formalização e contínua prática de leitura e escrita, num processo permanente, por meio do qual se espera a formação plena para fins de se alcançar sucesso no processamento linguístico em múltiplos eventos comunicativos. A multitarefa a que somos exigidos requer esforço cognitivo positivo, como apontam Dudeney, Hockly, Pegrum (2016:43), mas também negativo, com o risco de sobrecarga mental com resultado nulo de aprendizagem. Há que se ter equilíbrio no jogo hipermidiático que também não pode se reduzir à ludusfera (Larizzati, 2013), em que só resta o brinquedo do caleidoscópio observado pelo olho mágico.

\section{REFERÊNCIAS}

AZEVEDO, C. Alfabetização e Letramento: qualidade e desigualdade. In: .; SOUZA NETO, J. C. (org.). Estudos e Práticas de Alfabetização e Letramento. 1aㅡ ed. São Paulo: Expressão \& Arte Editora. 2012. 112p. 
BATISTA, H. R; MOLLICA, M. C. Public Virtual Rooms of Learning: an emerging technology resource. Creative Education. vol.5, n. 8, May 2014.

BARRETO, K. H. Os memes e as interações sociais na internet: uma interface entre práticas rituais e estudos de face. Tese de Doutorado. Juiz de Fora: UFJF, 2015.

BARTON, D.; LEE, C. Linguagem online: textos e práticas digitais. Tradução: Milton Camargo Mota. São Paulo: Parábola Editorial, 2015.

BRASIL. Presidência da República. Secretaria de Comunicação Social. Pesquisa brasileira de mídia 2015: hábitos de consumo de mídia pela população brasileira. Brasília: SECOM, 2014.

COELHO, E. Q.; CARDOSO, J. E. D.; COELHO, A. Q. Informações médicas na internet afetam a relação médico-paciente?. Revista Bioética (Online) , v. 21, p. 142149, 2013.

COSCARELLI, C. V. Da leitura de hipertexto: um diálogo com Rouet et al. In: ARAUJO, J. C.; BIASI-RODRIGUES, B. (orgs.). Interação na internet: novas formas de usar a linguagem. Rio de Janeiro, Lucerna: 2005.

DIONISIO, A. P.; VASCONCELOS, L. J. de. Multimodalidade, gênero textual e leitura. In: BUNZEN, C.; MENDONÇA, M. Múltiplas linguagens para o ensino médio. São Paulo: Parábola, 2013.

DUDENEY, G.; HOCKLY, N.; PEGRUM, M. Letramentos digitais. Tradução: Marcos Marciolino. São Paulo: Parábola Editorial, 2016, p. 43.

FOTOS ANTES E DEPOIS. Disponível em: https://www.fotosantesedepois.com/clareamento-dental-caseiro/ Data de acesso: 20/11/2017.

FREITAS, M. T. Letramento digital e formação de professores. Educação em Revista, Belo Horizonte, v. 26, n. 3, p. 335-352, jul/dez.2010.

HELMAN, C. G. Cultura, saúde e doença. Tradução: Ane Rose Bolner. 5 ed. Porto Alegre: Artmed, 2009. 432p.

GONÇALVES, M. Wikipédia na produção discursiva do conhecimento. In: MOLLICA, Maria Cecília; BATISTA, H. R.; GUIMARÃES, L. S. (Orgs). Cybercorpora e inovação com práticas de ensinagem. 1 ed, Curitiba: CRV, 2015

GONÇALVES, M.; L., MONTENEGRO, C. R. Validação discursiva da informação. Linguagem \& Ensino, Pelotas, v.17, n.3, p.901-925, set./dez. 2014.

GUIMARÃES, L. S. Os sujeitos e as subjetividades em ambientes virtuais de aprendizagem. In: BATISTA, H. Ribeiro; MOLLICA, M. C.; PATUSCO SILVA, C. (Orgs.). Sujeitos em ambientes virtuais. Festschriften para Stella Maris BortoniRicardo. 1ํㅡ. ed. São Paulo: Parábola Editorial, 2015. 
GOULART, E. E. O docente nas mídias sociais. In: Mídia sociais: uma contribuição de análise. Comunicação \& Inovação, v. 5. Porto Alegre: EdiPUCRS, 2014.

IPM. Inaf: Relatórios do Instituto Paulo Montenegro. Disponíveis em: http://www.ipm.org.br/pt-br/programas/inaf/Paginas/default.aspx . Data de acesso: 29 de maio de 2016.

ILIOVITZ, E. R. É preciso ler muito para escrever bem? Uma análise dos hábitos de leitura ... 59 Revista Horizontes de Lingüística Aplicada, v. 7, n. 1, p. 59-70, 2008.

KLEIMAN, A. Modelos de alfabetização e as práticas de alfabetização na escola. In (org). Os significados do letramento. Uma nova perspectiva sobre a prática social da escrita. São Paulo: Mercado das Letras, 1995. p.15 - 61.

LANDOW, G. P. Hipertexto: La convergencia de la teoría crítica contemporánea y de la tecnología. Barcelona: Paidós. 1992.

LARIZZATI, D. Ludusfera: o espaço do jogo hipermidiático. Rumores, número 13, volume 7, janeiro-junho 2013.

LEAL, M.; MOLLICA, M. C. Funções de elementos figurativos na leitura. Ecos de Linguagem. $2015 . \quad$ Disponível em: http://anpoll.org.br/portal/wpcontent/uploads/2015/07/ecos de linguagem 6.pdf. Acesso em: 19 de maio de 2016.

Português e matemática: parceria indispensável em política educacional. IN: DA HORA. Demerval et alli (Org.). Linguística: práticas pedagógicas. Santa Maria: Editora Pallotti, 2006.

. Letramento em EJA. São Paulo: Parábola Editorial, 2009.

. Competências subjacentes à leitura: pilares de acesso aos saberes formais. IN: MOLLICA, Maria Cecilia; LEAL, Marisa (Org.). Construindo o Capital Formal das Linguagens. Curitiba: Editora CRV, 2010.

.. Lendo Matemática. IN: BORTONI-RICARDO et al. Leitura e Mediação Pedagógica. São Paulo: Parábola Editoria, 2012, pp. 181-202.

MAINART, D. A.; SANTOS, C. M. A importância da tecnologia no processo ensinoaprendizagem. $\quad$ Convibra, $2010 . \quad$ Disponível em: <http://www.convibra.com.br/upload/paper/adm/adm_1201.pdf>

MAIA, M. R. A informação sobre saúde bucal no mundo digital. Tese em andamento (Doutorado em Ciência da Informação IBICT/UFRJ), Rio de Janeiro, 2017.

MARCUSCHI, L. A. Produção textual: análise de gêneros e compreensão. São Paulo: Parábola, 2008. 
MARCUSCHI, L. A.; XAVIER, A. C. Hipertexto e gêneros digitais. Rio de Janeiro: Lucerna, 2004.

MOLLICA, M. C. Redes sociais em grandes centros urbanos: um estudo sociolinguístico no Rio de Janeiro. IN: Terceira Margem. Revista da Pós-graduação em Letras da UFRJ, ano III, n.3, 1995, p. 156-161

MORAN, J. M. Novas tecnologias e o reencantamento do mundo. Revista Tecnologia Educacional. Rio de Janeiro: vol. 23, n. 2, p. 126, set. / out. 1995.

OLIVEIRA, R. N. C. 0 agir comunicativo no contexto das práticas de educação em saúde pública: um estudo à luz da teoria da ação comunicativa de J. Habermas. Serv. Soc. Soc., São Paulo, n. 106, p. 267-283, abr./jun. 2011.

PACHECO, J. A.; PEREIRA, N. Globalização e identidades educativas: rupturas e incertezas. Revista Lusófona de Educação, n.8, p.13-28, 2006.

PLETNEVA, N; CRUCHET, S.; SIMONET M.; KAJIWARA, M.; BOYER, C. Results of the 10th HON survey on health and medical Internet use. Stud Health Technol Inform. 2011;169:73-7.

SILVA, C. D. C. Informação em saúde: produção, consumo e biopoder. Ciência \& saúde coletiva [online]. 2013, vol.18, n.10, p. 3083-3090.

SOARES, M. Letramento e escolarização. In: RIBEIRO, V. M. (org). Letramento no Brasil. Reflexões a partir do INAF 2001. 2 ed. São Paulo: Global, 2003. p. 89 - 114.

SOARES, M. Novas práticas de leitura e escrita: letramento na cibercultura. Educ. Soc. Campinas, vol. 23, n. 81, dez, 2002.

XAVIER, A. C. Letramento digital e ensino. In: FERRAZ, C.; MENDONÇA, M. Alfabetização e letramento: conceitos e relações. Belo Horizonte: Autêntica, 2007. 